\title{
O PROCESSO DE ENSINO APRENDIZAGEM EM GERENCIAMENTO DE PROJETOS E A INSERÇÃO SOCIAL: A EXPERIÊNCIA DA CASA DE CÁRITAS
}

\author{
THE TEACHING LEARNING PROCESS IN \\ PROJECT MANAGEMENT AND SOCIAL INCLUSION: \\ THE CASA DE CÁRITAS EXPERIENCE
}

Recebido em: 19/01/2012 Aprovado em: 25/03/2012 Avaliado pelo sistema double blind review Editora Científica: Manolita Correia Lima

\author{
LEANDRO COSTA SCHMITZ leandro@schmitz.eng.br \\ GRAZIELA DIAS ALPERSTEDT \\ UNIVERSIDADE DO ESTADO DE SANTA CATARINA \\ HANS MICHAEL VAN BELLEN \\ UNIVERSIDADE FEDERAL DE SANTA CATARINA
}

JANAINA LOPES SCHMITZ
CENTRO DE EDUCAÇÃO SUPERIOR - UNICA/SOCIESC

\section{RESUMO}

No sentido de contribuir para a discussão sobre aprendizagem pela experiência ou na ação, este artigo objetiva apresentar o processo de ensino aprendizagem desencadeado na disciplina de gerenciamento de projetos, com base na efetiva execução de um projeto social por alunos de um curso de graduação em administração no sul do país. Os fundamentos teóricos baseiam-se nas abordagens de aprendizagem, que defendem a aquisição de saberes mais abrangentes por meio da experiência com a resolução de problemas reais (SCHÖN, 2000a; 200ob; PERRENOUD, 2002; MITRE et al., 2008). O método consistiu na aplicação da metodologia de ensino aprendizagem descrita pelos autores, que pode ser resumida pela definição de uma instituição a ser beneficiada (Casa de Cáritas), na elaboração de um planejamento de ações para atender demandas identificadas, na execução dessas ações em meio a um processo de monitoramento, observando boas práticas de gerenciamento de projetos propostas pelo PMI (2008). Além da apresentação da experiência em si, o artigo evidencia os resultados do projeto, as lições aprendidas pelos alunos e ainda revela o caráter social desse tipo de iniciativa.

Palavras-chave: aprendizagem pela experiência; gerenciamento de projetos; projetos sociais.

\section{ABSTRACT}

In an effort to contribute to the discussion about leaning through experience or in practice, the objective of this paper is to demonstrate the teaching/learning process used in the project management discipline based on the effective execution of a social project by the students of a management graduate course in southern Brazil. The theoretical foundations are based on learning techniques that focus on the acquisition of more comprehensive knowledge through experience in troubleshooting real problems (SCHÖN, 2000a; 2000b; PERRENOUD, 2002; MITRE et al., 2008). The method comprised the application of the teaching-learning methodology described by the authors, which may be summarized as defining the institution to be helped (here, the Casa de Cáritas), drawing up an action plan to meet the demands identified, carrying out these actions alongside a respective monitoring process, and complying with the project management best practices proposed by the PMI (2008). In addition to the experience itself, the paper highlights the project's results, the lessons learned by the students and reveals the social character of this kind of initiative.

Keywords: learning through experience; project management; social projects. 


\section{INTRODUÇÃO}

O contexto reducionista em que se inserem os programas de formação dos novos administradores já foi objeto de estudo de muitos pesquisadores. Schmitz, Alperstedt e Moraes (2008) concentraram-se na análise de uma disciplina específica presente nos cursos de graduação em administração, qual seja o gerenciamento de projetos.

Os autores destacaram que um projeto, de forma geral, tem uma forte orientação prática, o que levantaria dúvidas sobre as formas habituais de condução do processo de ensino/aprendizagem dessa disciplina desenvolvido nas escolas de administração. Embora não seja uma exclusividade do gerenciamento de projetos, seu caráter eminentemente prático exige por parte do professor a adoção de metodologias que permitam ao aluno também uma aprendizagem na prática, fugindo de soluções predeterminadas (PIAGET, 1998).

O princípio fundamental para esse desafio reside na ideia de que verdades reais somente são construídas livremente. Além disso, o bem moral é autônomo, o que torna inválida a prescrição (PIAGET, 1998). Assim, a imposição de verdades, mesmo que evidentes, pode prejudicar a aprendizagem dos indivíduos, uma vez que são determinadas de fora para dentro, não sendo construídas pelo próprio indivíduo. Nesse sentido, a aprendizagem pela experiência é sempre superior àquela transmitida por outras pessoas, ao mesmo tempo em que a metodologia de construção do conhecimento tende a ser mais efetiva se comparada ao conhecimento já produzido socialmente (DUARTE, 200I).

Considerando que a complexidade do mundo, na atualidade, requer múltiplos saberes por parte dos profissionais (LE BOTERF, 2003), exigindo formas inovadoras de exercício do magistério, Schmitz, Alperstedt e Moraes (2008) resgataram as ideias de Schön (2000a; 200ob) sobre a importância do profissional reflexivo, a reabilitação da razão prática, a aprendizagem por meio da experiência e a utilização da intuição e da reflexão na ação. Às ideias de Schön foram somadas as de Perrenoud (2002) aplicada ao trabalho do professor, para quem o desafio está justamente em ir além do 
conhecimento de conteúdos teóricos, alcançando um conjunto de saberes mais abrangentes, didáticos e transversais, os quais são adquiridos ao longo da experiência e que influenciam, por sua vez, a aprendizagem dos alunos.

Com o intuito de contribuir não somente para essa discussão no sentido teórico, mas para o desenvolvimento de práticas alternativas reais de ensino/aprendizagem, objetiva-se com este artigo apresentar o processo de ensino aprendizagem proposto e desencadeado com base em um projeto desenvolvido por alunos de um curso de graduação em administração no sul do país, conduzido durante a disciplina de gerenciamento de projetos. Nesse sentido, o artigo está vinculado ao tema "o processo de ensino na administração e na contabilidade".

A experiência aqui relatada vincula-se à metodologia descrita por Schmitz, Alperstedt e Moraes (2008). Trata-se de um trabalho desenvolvido pelos alunos da oitava fase de um curso de graduação em administração que contempla todos os processos de gerenciamento de um projeto, culminando em sua implantação efetiva. Além da apresentação da experiência em si, o projeto revela um caráter social, beneficiando uma organização social, a Casa de Cáritas, localizada no entorno da instituição, demonstrando o caráter de inserção social do curso ao qual a disciplina se vincula. 


\section{REFERENCIAL TEÓRICO}

\section{PROCESSO DE ENSINO/APRENDIZAGEM, AUTONOMIA INDIVIDUAL E RESOLUÇÃO DE PROBLEMAS}

O desenvolvimento da autonomia individual em íntima coalizão com o coletivo é destacado por Mitre et al. (2008) como um dos grandes desafios deste século. Para isso, a educação que objetiva a visão do todo, a interdependência e a transdisciplinaridade devem ser desencadeadas. Nesse sentido, a educação deve ser capaz de permitir a construção de redes de mudanças sociais, aliada à expansão da consciência individual e coletiva. À frente disso estão métodos inovadores, que preconizam uma prática pedagógica ética, crítica, reflexiva e transformadora, e que permitam, ao mesmo tempo, ultrapassar as fronteiras do treinamento eminentemente técnico, para, de fato, atingir a formação do homem como um ser histórico e consciente da dialética da ação-reflexão-ação (MITRE et al., 2008).

Em detrimento da perspectiva inovadora, a formação dos profissionais na área de administração tem sido historicamente baseada na utilização de metodologias conservadoras inspiradas no mecanicismo cartesiano, por natureza fragmentado e reducionista (SERVA; DIAS; ALPERSTEDT, 20IO). Nesse quadro inspirador, o corpo é separado da mente, a ciência da ética, a razão do sentimento e onde, em nome da eficiência técnica, os saberes são compartimentados em disciplinas separadas. Assim, o processo ensino aprendizagem, da mesma forma contagiado, limita-se, na maioria das vezes, à mera reprodução do conhecimento, no qual o professor desempenha um papel de transmissor de conhecimentos e ao aluno, por sua vez, é reservado o papel de retentor e repetidor de conteúdos de uma forma meramente passiva e, muitas vezes, sem a necessária visão crítica e reflexiva.

Por outro lado, as metodologias ativas baseiam-se na autonomia, ou algo explícito, segundo Freire (2006), que pressupõem um aluno com capacidade de autogerenciamento ou autogoverno no que se refere ao seu processo de formação. Alves (2003) salienta que a atividade de aprendizagem deve envolver a participação de todos aqueles que nela estão envolvidos. Nesse 
sentido, ela pressupõe a autoiniciativa, e quando engloba as dimensões afetivas e intelectuais, tende a ser mais sólida e duradoura (ROGER, I986).

Olhando sob a perspectiva do aprendiz, o método deve permitir que a aprendizagem represente um processo de reconstrução, que seja capaz de conduzir ao estabelecimento de variados tipos de relações entre fatos e objetos, estimulando e permitindo as ressignificações/reconstruções e proporcionando a utilização da experiência aprendida em situações diversas (DEMO, 2004).

Coll (2000) salienta a existência de dois requisitos para que a aprendizagem seja efetiva. São eles: um conteúdo significativo e uma atitude favorável para a aprendizagem. Nesse sentido, a predisposição do aluno torna-se importante, pois origina o estabelecimento de associações entre os novos elementos a aprender e aqueles já existentes em sua estrutura cognitiva, ao contrário da aprendizagem mecânica, que não favorece o estabelecimento de relações entre o novo e o anteriormente aprendido.

As metodologias consideradas ativas valem-se da problematização como estratégia de ensino aprendizagem (CYRINO; TORALLES-PEREIRA, 2004). Seu objetivo é o de motivar o aluno, "pois diante do problema, ele se detém, examina, reflete, relaciona a sua história e passa a ressignificar suas descobertas" (MITRE et al., 2008, p. 2136). A problematização permite ao aluno entrar em contato com as informações e com a produção do conhecimento, tendo em vista a solução dos impasses a ele conferidos, além da promoção de seu próprio desenvolvimento. "Ao perceber que a nova aprendizagem é um instrumento necessário e significativo para ampliar suas possibilidades e caminhos, esse poderá exercitar a liberdade e a autonomia na realização de escolhas e na tomada de decisões" (MITRE et al., 2008, p. 2I36).

Para Dewey (1959), a problematização enfatiza o aluno como um sujeito ativo, o qual, baseado em uma experiência autêntica, com objetivos definidos, instigantes e que estimulem o pensamento, tenderá a buscar informações e meios adequados a fim de alcançar resultados concretos, comprovando os conteúdos aprendidos por meio de sua aplicação prática. Freire (2006), da mesma forma, destaca a problematização por meio da ênfase na práxis, permitindo ao sujeito a busca por soluções para lidar com 
a realidade em que vive, tornando-o capaz de transformá-la por sua própria ação. Por meio da ação, novos problemas são detectados, originando um processo contínuo de buscas e transformações. Esse processo possibilita ao aprendiz discutir os conflitos inerentes ao problema, evitando as conclusões rápidas, simplificadas ou massificantes. A problematização, para Berbel (1998), permite ao sujeito o alcance de algumas etapas que o levará a refletir sobre uma situação concreta, complexa e dinâmica, exercitando a prática de forma a criar consciência da práxis.

Santos (2005) e Cyrino, Toralles-Pereira (2004) destacam a complexidade e o caráter dinâmico do processo de ensino aprendizagem, o que exige do professor ações direcionadas ao aprofundamento e à aplicação de significados elaborados pelos alunos durante sua participação na resolução de problemas concretos. Isso exige por parte do professor o exercício permanente do trabalho reflexivo, da disposição para o acompanhamento, da pesquisa e do cuidado exigidos pelos aspectos emergentes das situações imprevistas e desconhecidas (MITRE et al., 2008). Nesse sentido, o processo de ensino aprendizagem pressupõe uma variedade de atividades integradas, que exige responsabilidade e comprometimento dos atores participantes, discentes e docentes.

Nesse processo, não somente o professor tem papel ativo, mas o aluno necessita assumir um papel cada vez mais ativo, aprendendo a buscar conhecimentos necessários à resolução dos problemas aos quais foi submetido e descondicionando-se da atitude de mero receptor de conteúdos. Santos (2005) destaca a iniciativa criadora, a curiosidade científica, o espírito críticoreflexivo, a capacidade para autoavaliação, a cooperação para o trabalho em equipe, o senso de responsabilidade e a ética como características essenciais a serem buscadas no profissional em formação.

Ao docente é necessário o desenvolvimento de novas habilidades, como a motivação e a competência para permitir ao discente a participação ativa no seu processo de aprendizagem. Demo (2004) destaca o papel de reconstrutor do conhecimento por parte do professor, não somente pela ótica da ciência e tecnologia, mas, sobretudo da humanização na educação, cuidando da aprendizagem e da formação crítica e criativa de um cidadão. 
Ainda nesse sentido, Freire (2006) critica a prática anti-humanista do professor como educador pragmático neoliberal, acusando-o de treinador, exercitador de destreza e transferidor de saberes, o qual se concentra em práticas eminentemente tecnicistas, colocando o aluno em uma situação de acomodação. O educador formador, por outro lado, caracterizaria aquele que permite uma "prática educacional viva, alegre, afetiva, extremosa, com todo rigor científico e o domínio técnico necessários, mas sempre em busca da transformação" (MITRE et al., 2008, p. 2138).

No que se refere à avaliação, qualquer estratégia inovadora deve considerá-la integrada à reflexão, a fim de também transformá-la por meio de um processo formativo que considere a inclusão, a autonomia, o diálogo e as reflexões coletivas, na busca de meios e soluções para os problemas enfrentados (PERRENOUD, 1999). Tais práticas avaliativas valem-se não da punição e da estigmatização, mas de diretrizes para a tomada de decisões e definição de prioridades. Da mesma forma que o processo de ensino aprendizagem, a avaliação deve promover uma reflexão crítica a respeito da prática, compreendendo seus progressos, resistências e dificuldades, além de possibilitar decisões sobre as ações subsequentes (BECKER, 200I).

Para que a avaliação inovadora se fundamente na colaboração e no empenho com a nova formação, torna-se necessário um planejamento e uma execução que envolva todos os participantes no processo. Assim, instrumentos de avaliação tradicionais tendem, nesse contexto, a serem substituídos pelo acompanhamento do processo, distanciando-se da mera apreensão e memorização de conteúdos ligados unicamente à esfera cognitiva. Nesse sentido, registros, autoavaliação e diálogo são exemplos de estratégias balizadoras desse processo, considerando o desenvolvimento do aluno em relação à autonomia, à criatividade, à capacidade de organização, à sua participação e a condições de elaboração, bem como ao seu relacionamento com o grupo e sua comunicação (MITRE et al., 2008). A autoavaliação pode permitir a revisão da metodologia utilizada na prática pedagógica, ao mesmo tempo em que o aluno reflete sobre si mesmo e sobre o conhecimento adquirido (VASCONCELLOS, 1988). 


\section{O GERENCIAMENTO DE PROJETOS}

É difícil precisar a origem do gerenciamento de projetos, pois as grandes obras da antiguidade já evidenciavam a necessidade de alguma forma de planejamento e organização do trabalho ora realizado. Entretanto, Codas (1987) argumenta que o gerenciamento de projetos moderno surgiu demandado pela crescente complexidade das operações militares, que, além do grande porte, envolviam a articulação de forças armadas de diversos países. Após o período da Segunda Grande Guerra, Meredith e Mantel Jr. (2003) assinalam a ocorrência de uma onda de popularidade no começo da década de 1960, destacando que foi um projeto bem sucedido que colocou o homem na Lua.

No Brasil, o desenvolvimento do gerenciamento de projetos trilhou um caminho próximo ao de outras partes do mundo, com aplicação principal em grandes obras de construção e projetos industriais, sob forte influência norteamericana (CODAS, 1987). O mesmo autor afirma que na década de I970 surgiram no Brasil duas organizações profissionais de gerenciamento de projetos: uma divisão do Project Management Institute - PMI e o Grupo de Estudos em Gerência de Empreendimentos de São Paulo (Gege).

Codas (1987) evidencia que foi apenas em 1983 que surgiu o primeiro curso de aperfeiçoamento em gerenciamento de projetos, promovido pelo Instituto Mauá de Tecnologia e a empresa Planasa, com duração de seis meses. No mesmo período, na Escola de Administração de Empresas de São Paulo, da Fundação Getúlio Vargas, houve o curso de pós-graduação em Gerenciamento da Implantação de Empreendimentos (CODAS, 1987). A partir desse período, a disciplina de gerência de projetos passou gradativamente a fazer parte do currículo dos cursos de graduação afins. Atualmente é uma disciplina recorrente nos currículos dos cursos de engenharia, economia e administração.

A abordagem de gerenciamento de projetos dominante no Brasil está baseada no padrão contido no Guia do Conhecimento em Gerenciamento de Projetos (Guia рмвок), publicado pelo Project Management Institute. Dessa forma, as normas, métodos, processos e práticas estabelecidos nesse padrão 
são uma importante referência de conteúdo programático e de referencial bibliográfico para as disciplinas ministradas nas instituições de ensino superior em todo o país.

O PMI (2008, p.5) enuncia projeto como "um esforço temporário empreendido para criar um produto, serviço ou resultado exclusivo" e seu gerenciamento como "a aplicação de conhecimento, habilidades, ferramentas e técnicas às atividades do projeto a fim de atender aos seus requisitos" (p.6). A abordagem de gerenciamento de projetos proposta pelo PMI (2008) requer a aplicação de processos apropriados e, por esse motivo, a versão da publicação atual descreve com detalhes as entradas, ferramentas e técnicas, e saídas de 42 processos de gerenciamento de projetos. Esses processos estão agrupados em cinco categorias, conhecidas como grupos de processo do gerenciamento de projetos: iniciação (2 processos); planejamento (20 processos); execução (8 processos); monitoramento e controle (Io processos) e encerramento (2 processos).

Além da categorização em cinco grupos de processo, o PMI (2008) também agrupa os processos em nove áreas de conhecimento, desenvolvidas resumidamente a seguir, contemplando seus objetivos e principais entregas:

a) Gerenciamento da integração do projeto: coordena os vários processos e atividades dos grupos de processo de gerenciamento. Possui processos em todos os grupos de processo: desenvolver o termo de abertura, desenvolver o plano de gerenciamento do projeto, orientar e gerenciar a execução, monitorar e controlar o trabalho, realizar o controle integrado de mudanças e encerrar o projeto ou fase;

b) Gerenciamento do escopo do projeto: assegura que o projeto inclui o trabalho necessário para terminar o projeto com sucesso. Seus processos são: coletar os requisitos, definir o escopo (declaração do escopo do projeto), criar a estrutura analítica do projeto - EAP, verificar e controlar o escopo;

c) Gerenciamento do tempo do projeto: gerencia o término pontual do projeto. Seus processos baseiam-se na definição de atividades, passam por processos necessários para o desenvolvimento do cronograma, como o sequenciamento de atividades, estimativa de recursos e de duração das atividades, e terminam com o controle do cronograma; 
d) Gerenciamento dos custos do projeto: inclui os processos de estimativa de custos, determinação do orçamento e controle de custos, de modo que o projeto possa ser terminado dentro do orçamento aprovado;

e) Gerenciamento da qualidade do projeto: determina as políticas de qualidade, os objetivos e as responsabilidades, de modo que o projeto satisfaça as necessidades para os quais foi empreendido. Seus processos são: planejar a qualidade, realizar a garantia da qualidade e realizar o controle da qualidade;

f) Gerenciamento dos recursos humanos do projeto: organiza e gerencia a equipe do projeto. Seus processos são: desenvolver o plano de recursos humanos, mobilizar e desenvolver e gerenciar a equipe do projeto;

g) Gerenciamento das comunicações do projeto: assegura que as informações sejam geradas, coletadas, distribuídas, armazenadas, recuperadas e organizadas de maneira oportuna e apropriada. Para isso consideram os seguintes processos: identificar as partes interessadas, planejar as comunicações, distribuir as informações, gerenciar as expectativas das partes interessadas e reportar o desempenho;

h) Gerenciamento dos riscos do projeto: objetiva aumentar a probabilidade e o impacto dos eventos positivos e reduzir a probabilidade e o impacto dos eventos negativos. Seus processos são: planejar o gerenciamento de riscos, identificar os riscos, realizar a análise qualitativa e quantitativa, planejar as respostas aos riscos e monitorar e controlar os riscos;

i) Gerenciamento das aquisições do projeto: inclui processos necessários para comprar os produtos e serviços necessários ao projeto, externos à sua equipe. Para tanto, os processos sugeridos são o planejamento, condução, administração e encerramento das aquisições.

De acordo com a abordagem do PMI (2008), cujo resumo foi apresentado acima, os processos do gerenciamento de projetos não precisam ser aplicados de maneira uniforme em todos os projetos: "para qualquer projeto específico, o gerente de projeto, em colaboração com a equipe do projeto, sempre é responsável por determinar quais processos são apropriados e o grau de rigor apropriado para cada um" (PMI, 2008, p. 38). Com base na importância assumida pelos gestores e profissionais de projetos, inclusive na 
determinação da melhor composição de processos, ferramentas e técnicas para gerenciar um projeto específico, pode-se inferir que a experiência em projetos e em sua área de aplicação são fatores importantes para profissionais que almejam trabalhar com projetos.

O próximo tópico inicia o relato de uma abordagem de ensino que proporciona aos alunos uma primeira experiência com a participação e o gerenciamento de um projeto real, contribuindo para sua formação na área por meio de uma situação de aprendizagem na prática. 


\section{METODOLOGIA DE ENSINO/APRENDIZAGEM}

Um breve histórico da abordagem de implantação de um projeto como alternativa para aplicação dos processos de gerenciamento de projetos na disciplina de mesmo nome, recorrente nos currículos de cursos de graduação em administração é apresentado no artigo publicado por Schmitz, Alperstedt e Moraes (2008). A realização efetiva de um projeto na disciplina permite a contemplação de todos os grupos de processos - iniciação, planejamento, execução, monitoramento e controle e encerramento - sugeridos pelo PMI (2008) em seu guia de boas práticas em gerenciamento de projetos.

A realização dessa dinâmica na disciplina de gerenciamento de projetos vem sendo aplicada desde o primeiro semestre de 2005. Em números, são seis anos de experiência e 29 projetos executados, já que em alguns semestres foram realizados mais de um projeto por turma.

A disciplina apresenta carga horária de 60 horas/aula. Com relação à equipe é importante destacar que todos os alunos matriculados realizam o mesmo trabalho, ou seja, eles se auto-organizam em subgrupos e definem uma hierarquia. As turmas do turno vespertino possuem em média vinte e cinco alunos matriculados e as do período noturno quarenta.

Já na primeira aula, durante a discussão do plano de ensino, as iniciativas de projetos de turmas anteriores são apresentadas. Além disso, os alunos recebem a demanda de se reunir em duplas ou trios e trazer, para a aula seguinte, pelo menos uma ideia de projeto a ser realizado e uma instituição ou causa a ser beneficiada. Na prática, os alunos já conhecem preliminarmente o trabalho e chegam com muita curiosidade e dúvidas com relação à sua realização. Muitos gostariam de executar o projeto já a partir da primeira aula, o que pode ser considerado uma manifestação da tendência de ir direto para a ação, mesmo sem planejamento anterior, e a preocupação com a falta de tempo.

Ao evidenciar o direcionamento para a execução e a falta de tempo, uma das principais limitações dessa abordagem é destacada: a impossibilidade de um estudo aprofundado dos conceitos e processos da norma do pMI antes do início do projeto. A estratégia adotada nos últimos dois semestres para lidar 
com essa dificuldade foi a participação ativa do docente na realização de oficinas para elaboração dos documentos de formalização do planejamento do projeto. Nesse sentido, os alunos elaboram uma primeira versão do plano de gerenciamento do projeto, com base em explicações preliminares e em formulários desenvolvidos pelo professor, mas adaptados do material do PMI (2008) e no exemplo fornecido por Vargas (2009).

Para permitir o apoio de um software de gerenciamento de projetos, também são ministradas duas aulas no laboratório de informática com o software Microsoft Project. Ao final do décimo encontro, a versão preliminar do plano de gerenciamento do projeto é apresentada para a equipe. Maiores detalhes do plano de gerenciamento do projeto são fornecidos a seguir, no caso do Projeto Cáritas.

Mesmo durante a elaboração do plano de gerenciamento do projeto, os alunos já iniciam os primeiros passos de sua implantação. Entretanto, é apenas após o final da etapa de planejamento que se inicia a execução do projeto propriamente dito, com cada aluno possuindo atividades atribuídas para si, com prazos a serem cumpridos.

Durante todas as aulas do semestre o conteúdo teórico passa a ser ilustrado com exemplos da realidade que os alunos estão vivendo, além da preocupação com o monitoramento e controle das atividades desempenhadas. Cada turma estabelece um ou mais formatos de relatório de progresso, que podem ser um e-mail periódico, um quadro informativo na sala de aula, um painel de controle ou ainda reuniões específicas.

As avaliações ocorrem de acordo com uma metodologia pré-estabelecida, onde cada integrante se autoavalia e avalia os demais integrantes com os quais interagiu na execução do projeto. Dessa forma, os alunos recebem formulários de avaliação diferenciados por seu papel no projeto:

a) O gerente de projetos: avalia os líderes dos subgrupos de trabalho;

b) Os líderes dos subgrupos de trabalho: avaliam o gerente do projeto, os demais líderes dos subgrupos e os integrantes de seu subgrupo de trabalho;

c) Os integrantes do subgrupo de trabalho: avaliam os demais integrantes e o líder de seu subgrupo. 
É importante destacar que as avaliações possuem pesos diferentes: a autoavaliação possui peso de $20 \%$ do conceito total, a avaliação de seu superior $40 \%$ e a avaliação dos demais $40 \%$. No caso do gerente de projetos, como não há superior, sua avaliação corresponde a $20 \%$ de sua autoavaliação com $80 \%$ da avaliação dos demais. Também se salienta que são realizados dois momentos de avaliação: um aproximadamente na metade do período letivo e outro no final. A ideia é permitir que alunos que não estejam atingindo as expectativas na primeira avaliação tenham a oportunidade de se recuperar na segunda.

Além da avaliação final, ao término do semestre, os alunos realizam duas apresentações: uma voltada para a disciplina e a aplicação dos conceitos de gerenciamento de projetos e outra focada na prestação de contas para os parceiros e patrocinadores do projeto. 


\section{APRESENTAÇÃO DO PROJETO}

Após resumir a dinâmica do trabalho, neste tópico, será apresentado o caso de um dos projetos realizados pelos alunos no ano de 2010, iniciando com a abordagem da instituição selecionada.

\section{A CASA DE CÁRITAS}

Preliminarmente a escolha da instituição na qual o projeto será realizado parece ser uma tarefa simples, ainda mais se consideradas as dificuldades e desafios impostos à ampla maioria das organizações do terceiro setor. Entretanto, com um pequeno aprofundamento, verifica-se que essas instituições não estão tão abertas como previsto para a realização de trabalhos acadêmicos. Essa situação pode ser explicada principalmente de duas formas, considerando a experiência anterior das instituições:

a) Grupos de alunos, notadamente dos cursos de pedagogia, psicologia, administração e administração pública, entre outras, costumam procurar as instituições com a promessa de auxiliar no desenvolvimento e melhoria de seus trabalhos rotineiros, mas acabam por apenas cumprir com os requisitos do trabalho acadêmico que lhes foi demandado. Em outras palavras: os alunos procuram as instituições para resolver um problema deles - fazer um trabalho acadêmico solicitado por alguma disciplina - e não para auxiliar essas organizações a lidar com seus próprios problemas.

b) Promessas políticas, principalmente em períodos eleitorais, recorrentemente não são cumpridas, caracterizando o descrédito das instituições com as possibilidades de ajuda externa.

O resultado esperado dessa contextualização é o investimento de tempo do pessoal dessas instituições, muitos dos quais voluntários, para ajudar os alunos ou políticos a cumprirem seus objetivos, sem que ocorra uma retribuição justificável. Não é objetivo de este trabalho evoluir essa problemática, mas a consequência que se pretende destacar é a dificuldade de encontrar instituições que estejam dispostas a participar e se comprometer com iniciativas externas, que prometem resultados e benefícios que, geralmente, não são entregues. 
Para driblar essa dificuldade, os alunos costumam apresentar projetos que foram realizados anteriormente na disciplina e colocam à disposição os contatos de dirigentes das instituições beneficiadas como referência do trabalho realizado. A escolha da instituição a ser beneficiada com os resultados do projeto é feita pelos alunos no início do trabalho, quando os interessados apresentam preliminarmente algumas possibilidades. Destacam-se as instituições que fornecem cuidados a crianças e idosos.

A Casa de Cáritas é uma instituição que é o lar de crianças com necessidades especiais e que ainda foram vítimas de maus tratos, de forma que a justiça tirou dos pais e responsáveis a guarda dessas crianças. A história do Recanto de Cáritas, como é conhecido o lugar específico que abriga as crianças na instituição, é marcada pelo altruísmo e doação de um casal. Com a ajuda de poucos amigos e familiares, eles investiram suas reservas financeiras na compra de um terreno no bairro de Forquilhinhas, município de São José/SC e construíram nela as instalações da instituição, que funciona como um centro espírita e que, inicialmente, trabalhava com a distribuição de alimentos e sopa para comunidades carentes.

Durante as atividades do casal na comunidade do sertão do Maruí, foi que eles encontraram a primeira moradora do recanto. A menina sofre de autismo (uma doença neurológica que leva à dificuldade de interação com o meio externo) e vivia escondida no porão de uma casa, junto com outros animais de estimação. Tratada como um bicho, seus pais chegavam a lhe dar banho com uma mangueira de água gelada, em pleno inverno. O encontro com a menina e o posterior ganho de sua guarda na justiça representa o início do atendimento às crianças na instituição.

Atualmente, a casa abriga sete crianças com histórias não menos comoventes e a oportunidade de realização do projeto surgiu especificamente por conta das últimas duas que adentraram na instituição. Para o ganho da guarda de um casal de irmãos, também vitimados por maus tratos dos pais, a justiça determinou a necessidade de disponibilizar um quarto para ambos. Como a casa atual encontrava-se com os cômodos todos ocupados, os responsáveis pelo Recanto de Cáritas transferiram a cozinha para fora do imóvel, em um espaço inadequado e aberto. Nesse contexto 
fica caracterizada a carência da instituição e a situação que levou os alunos a contemplá-la, fazendo de sua necessidade imediata o objetivo do projeto.

\section{O PROJETO CÁRITAS}

No segundo semestre do ano de 20Io, os alunos do curso de administração vespertino do Centro de Ciências da Administração e Sócio-econômicas (ESAG) da Universidade do Estado de Santa Catarina (UDESC) escolheram contemplar a Casa de Cáritas como objeto da iniciativa de execução e gerenciamento de um projeto. Após algumas interações com o responsável pela instituição, visando a conhecer melhor suas demandas e priorizar suas necessidades, ficou definido que o objetivo geral do Projeto Cáritas seria reformar parte da estrutura física da "Instituição Filantrópica Casa de Cáritas".

Ao mesmo tempo em que a interação com a instituição ocorria, durante as aulas, os alunos trabalhavam no detalhamento do projeto e na geração dos primeiros documentos de formalização, destacando-se aqueles gerados como resultado dos processos de iniciação da abordagem de gerenciamento de projetos do PMI: o termo de abertura e a identificação das partes interessadas. O primeiro documento tem como função apresentar as definições iniciais do projeto e estabelecer preliminarmente seus principais requisitos. Nele as informações estão elaboradas em alto nível, ou seja, com pouco detalhamento. No termo de abertura foi apresentada uma primeira versão dos objetivos específicos do projeto, que permitiram a consecução do objetivo geral proposto:

a) Realizar happy hour solidário para arrecadar fundos;

b) Realizar uma corrida de rua para arrecadar fundos;

c) Obter recursos por meio de patrocinadores e parceiros;

d) Levantar mantenedores para a instituição.

Percebe-se que a realização da obra da reforma inicialmente ficou fora dos objetivos específicos, uma vez que boa parte da turma considerou que haveria uma inviabilidade com relação ao tempo disponível para a execução do projeto. Entretanto, cerca de seis ou sete alunos se comprometeram, por escrito, a finalizar a obra mesmo excedendo o final do semestre letivo. 
$\mathrm{Na}$ identificação das partes interessadas, foram incluídas, além da Casa de Cáritas, dos alunos e do professor, a UDESC/ESAG e outros potenciais parceiros e patrocinadores necessários para a realização dos eventos (happy hour e corrida) e da reforma.

Outro resultado do esforço de planejamento inicial do projeto foi a organização da turma em quatro áreas de trabalho (subgrupos) com a seguinte distribuição: operações (sete integrantes), marketing e captação (sete integrantes), administrativo (5 integrantes) e social ( 2 integrantes). Para cada subgrupo foram preliminarmente, definidas atribuições básicas e posteriormente, a turma escolheu o gerente do projeto e os líderes dos subgrupos de trabalho, estabelecendo uma hierarquia no projeto. Para a escolha, os interessados se identificaram e as posições foram negociadas e acordadas por todos.

$\mathrm{Na}$ sequência, como é de costume das turmas que realizam projetos na disciplina, cada participante da equipe do projeto doou vinte reais para a iniciativa. Com os recursos foram impressos os convites para o primeiro evento (happy hour), alguns planos para captação de recursos e também confeccionada uma camiseta do projeto. A camiseta possui um efeito simbólico muito importante, principalmente com relação ao reconhecimento como integrantes de uma equipe de projeto. Esses são os recursos com os quais o projeto é iniciado.

Seguindo a abordagem estabelecida pelo PMI, os alunos passam por alguns processos selecionados do grupo de processos de planejamento. Como saída dos processos, tem-se a formalização inicial de outros componentes do plano de gerenciamento do projeto. Nesse sentido, nas alíneas a seguir são apresentadas resumidamente algumas das definições resultantes dessa atividade:

a) Declaração do escopo do projeto e do produto do projeto A declaração do escopo do projeto validou os objetivos propostos no termo de abertura e evoluiu o detalhamento das entregas, dos requisitos, limites, premissas e restrições do projeto. Com relação às entregas, por exemplo, ficaram estabelecidos os seguintes: reforma, eventos, doações, mantenedores, divulgação de marcas parceiras, documentos do 
gerenciamento do projeto, prestação de contas e relatório final do projeto. Além disso, foi elaborado um documento de descrição do escopo do produto, especificando a reforma proposta, suas prioridades e critérios de aceitação. Os documentos relacionados com a área de gerenciamento do escopo ainda foram complementados com a estrutura analítica do projeto - EAP - que decompõe o trabalho a ser realizado.

b) Definição das atividades, recursos e prazos

Com base nos pacotes de trabalho definidos na estrutura analítica do projeto, foram identificadas as atividades que seriam realizadas por cada um dos subgrupos de trabalho do projeto e também a dependência por resultados ou trabalhos gerados por outras equipes. Para a realização dessa etapa do planejamento do projeto, os alunos foram conduzidos ao laboratório de informática, onde lhes foram ministradas duas aulas relacionadas à utilização do software MS-Project, disponível na instituição.

Após cada subgrupo estabelecer as atividades e seu sequenciamento, foram atribuídos os recursos disponíveis e necessários para a realização do trabalho, inclusive o participante responsável por cada uma das atividades. Posteriormente, foi estabelecida a duração da atividade. À equipe administrativa foi atribuída a tarefa de integrar os resultados do planejamento do tempo de cada uma das demais equipes, gerenciando as demandas conflitantes e consolidando o cronograma do projeto, apresentado para todos no formato de um gráfico de Gantt.

c) Orçamentação do projeto

Com base na necessidade de recursos estabelecida, o subgrupo administrativo foi também responsabilizado pela realização do orçamento do projeto. $O$ custo das horas de trabalho da equipe do projeto não foi contabilizado, mas apenas os recursos externos. Os materiais para a reforma da Casa de Cáritas foram os principais itens de custo, totalizando $\mathrm{R} \$ \mathrm{I} 8.568,8 \mathrm{o}$.

d) Plano de gerenciamento da qualidade O planejamento da qualidade trata de descrever quais serão os objetivos de qualidade perseguidos pelo projeto, seus indicadores e metas, bem como os fluxos para operacionalizar o controle. Entre os objetivos de qualidade e indicadores estabelecidos para o projeto destacam-se: comprometimento 
da equipe envolvida (percentual do total da equipe presente em reuniões), eficácia no alcance dos objetivos do projeto (número de participantes nos eventos) e satisfação dos participantes (pesquisa de avaliação - quantidade de avaliações como bom e muito bom). Para cada objetivo de qualidade foi também identificado um responsável.

e) Plano de gerenciamento dos recursos humanos

A abordagem da área de conhecimento dos recursos humanos do projeto foi bastante simplificada. Além da formalização do organograma do projeto e de uma matriz de responsabilidades, as necessidades de treinamento e consultoria foram supridas pelo professor da disciplina.

f) Plano de gerenciamento das comunicações

Dentro da área das comunicações, preliminarmente, foram identificadas treze partes interessadas no projeto. Para cada uma delas foi elaborado um conjunto de informações, que incluíam o papel no projeto, interesses e expectativas, classificação, influência e estratégia para interação.

Posteriormente, foi desenvolvido o plano de gerenciamento das comunicações que estabeleceu dezenove veículos de comunicação, entre os quais os e-mails internos e o grupo de discussão, as reuniões (geral, dos líderes e de cada área de trabalho), repositório de arquivos na internet (Google Docs), boletim informativo e site do projeto. Para cada veículo foi identificado o público-alvo, a frequência de comunicação e o responsável pela distribuição das informações.

g) Plano de gerenciamento de riscos

O gerenciamento dos riscos identificou vinte riscos a ser gerenciados, incluindo variações climáticas nos dias antecedentes e na data de realização da corrida, a segurança dos corredores, atrasos na reforma, atraso na liberação dos documentos de liberação da corrida pelo poder público e problemas com a captação de recursos.

Para cada um dos riscos elencados foram desenvolvidas informações complementares, como uma análise qualitativa da probabilidade de ocorrência e do impacto no projeto, a elaboração de um plano de contingências e a atribuição de um responsável pelo acompanhamento de cada risco. 
A área de conhecimento do gerenciamento das aquisições do projeto não foi contemplada com um plano específico, mas os alunos elaboraram um procedimento para a realização das compras do projeto, que foi apresentado para todos os envolvidos.

Passada a etapa de oficinas para a elaboração do plano de gerenciamento do projeto, aproximadamente no décimo encontro do semestre (um terço das aulas programadas), os alunos já possuíam disponível a primeira versão do documento. A partir daí, nas aulas subsequentes, o professor passa a abordar os processos apresentados pelo PMI organizados por área do conhecimento: integração, escopo, tempo, custos, qualidade, recursos humanos, comunicações, riscos e aquisições. Cada área do conhecimento é abordada em uma aula e os documentos produzidos pelos alunos são analisados pela turma à luz da teoria. As possíveis mudanças nos documentos vão sendo gerenciadas de acordo com seu impacto e comunicadas aos participantes do projeto.

Ao longo do semestre, os alunos executam o projeto e promovem processos de acompanhamento e controle do projeto. Para o Projeto Cáritas foram estabelecidas reuniões semanais de acompanhamento, informes realizados durante as aulas, atualização do cronograma e a utilização de um quadro fixado na parede da sala de aula com destaque de marcos do projeto e sua situação. Com um considerável esforço de todos os integrantes do projeto, o trabalho foi adequadamente conduzido e proporcionou os resultados evidenciados a seguir. 


\section{RESULTADOS OBTIDOS}

O presente tópico busca descrever os resultados obtidos com a realização do Projeto Cáritas. Inicialmente, serão contemplados os resultados dos eventos e da intervenção na instituição abrangida. Posteriormente, serão analisados os resultados relacionados à aprendizagem e à dinâmica do trabalho.

Como já mencionado, o aporte inicial de vinte reais por parte de cada aluno foi o pontapé inicial do projeto. Com a parceria com um dos bares da região, os alunos imprimiram e venderam ingressos para um happy hour, que, motivado por sua finalidade, foi chamado de help hour. Com este primeiro evento foram vendidos 363 ingressos, garantindo recursos para o andamento do projeto.

Somado a essa iniciativa inicial e após um treinamento em aula, os alunos saíram para buscar recursos com empresas munidos de seus planos de captação. A intenção era comercializar quotas de patrocínio para um evento maior, chamado Corrida de Cáritas, que reverteria todo o resultado para a instituição de mesmo nome. A ideia não é transferir os patrocínios diretamente para a instituição, mas investir em um evento que multiplicará o investimento recebido. Ao todo o projeto encontrou 8I apoiadores, entre pessoas físicas e jurídicas, que contribuíram com o recurso que estava disponível: insumo para a corrida, material de construção, dinheiro, doações diretas para a instituição, material de higiene e limpeza, espaço em mídia, entre outros. A captação de recursos junto a empresas sempre é uma atividade difícil, mas os alunos beneficiam-se do histórico de projetos realizados na disciplina e de empresas que recorrentemente fornecem apoio a essas iniciativas.

Com a difícil tarefa de levantar os recursos viabilizados, a Corrida de Cáritas foi realizada no dia o7 de novembro de 20ı, em Jurerê Internacional, com o apoio da Marinha e da Polícia Militar. Após aproximadamente dois meses e meio de planejamento, a corrida de rua reuniu mais de 700 pessoas, entre os quais 533 corredores.

A organização do evento foi considerada adequada, apesar da falta de experiência prévia dos alunos organizadores. A afirmação é atestada pelo 
resultado de uma pesquisa realizada pelos alunos com uma amostra de i76 corredores, da qual se destaca o percentual de satisfeitos e muito satisfeitos:

a) $82,96 \%$ com a organização;

b) $94,89 \%$ com o atendimento prestado;

c) $98,86 \%$ com o local da prova;

d) 98,86 participariam novamente da corrida.

Ao final da prova todos os corredores receberam uma medalha por sua participação. Os melhores em suas categorias também foram agraciados com medalhas distintas e troféus. As duas maiores emissoras de televisão aberta de Florianópolis estiveram presentes realizando matérias do evento em importantes programas jornalísticos regionais.

O resultado da corrida superou o esperado e gerou a quantidade de recursos necessários para a realização da reforma de parte da infraestrutura física na Casa de Cáritas. Antes mesmo do evento final de prestação de contas, o quarto especialmente adaptado para a criança autista já estava entregue, com paredes acolchoadas (de forma a evitar que ela se machucasse ao se debater) e colchão especial.

Devido à limitação de tempo do período letivo, o evento de prestação de contas com a participação dos parceiros e patrocinadores ocorreu durante a execução das obras de reforma da cozinha. Entretanto, como os recursos já haviam sido destinados, a prestação de contas não foi prejudicada. O evento evidenciou a satisfação dos parceiros e patrocinadores presentes com o resultado alcançado e abriu espaço para todos conhecerem melhor o impacto do projeto na Casa de Cáritas, por meio da manifestação do responsável pela instituição. Todos os presentes receberam um documento com os resultados de cada iniciativa do projeto e a evidenciação do destino dos recursos.

Aproximadamente vinte e cinco dias após o término do semestre, todos os envolvidos com o projeto, incluindo parceiros e patrocinadores receberam uma correspondência eletrônica indicando a finalização das obras de reforma da cozinha e, por consequência, do próprio projeto.

Por fim, cabe salientar que os alunos ainda conseguiram captar mais de cinco mil reais adicionais para investimento em móveis para equipar 
a cozinha, além de cadastrar e manter a instituição disponível no Portal Social, uma iniciativa da RBS TV, afiliada da Rede Globo, que qualifica instituições filantrópicas para recebimento de doações por meio da internet.

Finalizada a apresentação dos resultados do projeto, passa-se a considerar as contribuições desta dinâmica de trabalho, aplicada na disciplina de gerenciamento de projetos, para o processo de ensino e aprendizagem. Com essa finalidade, parece adequado contemplar as informações disponibilizadas pelos próprios alunos por meio das seguintes fontes:

a) Relatórios e documentos do projeto: todas as entregas dos alunos para o professor, incluindo o plano de gerenciamento do projeto, o plano de captação, os relatórios de progresso e o documento de prestação de contas;

b) Lições aprendidas: são elaboradas pelos alunos no final do projeto e entregues com um de seus resultados.

Por meio dessas fontes de informação infere-se a principal virtude dessa dinâmica, que é permitir o aprendizado por meio da ação. É na prática que os desafios abalam a confiança dos participantes e as dificuldades ocorrem e são transpostas. Nesse sentido, destaca-se, na visão dos alunos, o desafio que eles enfrentaram: "O questionamento mais complicado e demorado de responder: Quem acreditará em 22 estudantes e ajudará, com seus próprios recursos, o Projeto Cáritas a alcançar seus objetivos e melhorar a condição de vida de seis crianças mais que especiais?”.

A seguir, a evidenciação das dificuldades práticas encontradas pelos alunos participantes do projeto: "No decorrer do projeto, a maioria das decisões se tornava mais complicadas e cruciais. E, entre o emaranhado de dúvidas, havia apenas uma certeza: quanto mais decisões fossem tomadas, mais questionamentos surgiriam e o desafio mostrava-se maior do que parecia”.

A participação da iniciativa de execução de um projeto gerenciado de acordo com uma abordagem formalizada também permite aos alunos tirar algumas lições da experiência vivenciada. Nas alíneas seguintes encontrase uma seleção dessas lições aprendidas, que totalizaram cento e trinta e quatro registros: 
a) "O desenvolvimento de critérios claros e objetivos de avaliação poderão melhorar o desempenho das equipes se estas puderem acompanhar seu progresso ao longo do projeto”;

b) "A organização, comunicação e disponibilização de tarefas é a melhor forma de permitir a participação e envolvimento de todos os membros da equipe";

c) "Planeje e estimule prazos para todas as atividades. E cobre os prazos. O tempo é um dos recursos mais escassos e não deve ser tratado com descaso. Quando piscar os olhos, o projeto já acabou”;

d) "Não torne os problemas maiores do que são. É necessário ter calma e racionalidade em todos os momentos, porque problemas não irão faltar";

e) "Quando levar um problema para alguém se esforce para levar também uma solução. Se não a encontrar, divida o problema com o grupo. Não tome decisões precipitadas que possam afetar o projeto";

f) "Ninguém é igual e nem pensa igual; é preciso ter paciência e flexibilidade para considerar as ideias alheias e trabalhar melhor com o grupo";

g) "Quanto mais fazemos mais aprendemos. Se fazemos mais que os outros, isso é recompensado pelo aprendizado e o sentimento de missão cumprida";

h) "Comprovou-se que a motivação é algo intrínseco, não se pode motivar pessoas que não querem ser motivadas";

i) "Não se pode centralizar tudo, é preciso buscar confiar naqueles que merecem e repassar atividades mais simples e operacionais para aqueles que não estão tão dispostos a ajudar”;

j) “Todas as atividades devem ter um dono";

k) “Apesar de eu não acreditar muito, fazer um cronograma, estabelecer responsabilidades pode dar certo. Antes eu acreditava que isso não funcionava muito bem, mas funcionou".

Pode-se inferir, ao analisar a lista anterior, que as lições aprendidas pelos alunos representam um conjunto heterogêneo de aprendizado, abrangendo diversas temáticas e disciplinas diferentes. Algumas dessas lições, inclusive, 
nem podem ser extrapoladas para outros contextos e realidades. Entretanto, elas são genuinamente fruto da experiência dos próprios envolvidos, que atuam no processo de construção de seu aprendizado. 


\section{CONSIDERAÇÕES FINAIS}

O objetivo deste artigo foi o de apresentar o processo de ensino aprendizagem desencadeado com base em um projeto proposto e desenvolvido por alunos de um curso de graduação em administração no sul do país, conduzido durante a disciplina de gerenciamento de projetos. O desenvolvimento da metodologia de ensino/aprendizagem aqui relatada baseou-se na ideia de que a educação pode e deve ser um ato coletivo e comprometido que, quando imposto ou empurrado, pode não apresentar os resultados esperados (PIAGET, I998).

O resultado do trabalho proposto para os alunos demonstrou que, quando desafiados, eles se comprometem com um considerável esforço e gasto de energia, envolvendo e exigindo dos demais integrantes do projeto o cumprimento do papel para o qual se responsabilizaram (FREIRE, 2006; ALVES, 2003).

Os resultados evidenciaram também que a dinâmica aqui relatada contribuiu muito para o processo de ensino/aprendizagem, pois as lições aprendidas pelos alunos vão muito além do conteúdo programático, uma vez que representam um aprendizado transversal que engloba diversas temáticas e disciplinas variadas, resultando em um conjunto heterogêneo de aprendizado, enfatizando os argumentos de Santos (2005) e Cyrino e Toralles-Pereira (2004). Embora muitas dessas lições não possam ser aplicadas a outros contextos, elas resultam da experiência dos próprios alunos que atuaram de forma autônoma na construção de seu próprio aprendizado, conforme destacam Mitre et al. (2008).

A participação na execução do projeto gerenciado de acordo com uma abordagem formalizada permitiu, portanto, que os alunos tirassem suas próprias lições da experiência vivenciada, tal como advogam Santos (2005), Perrenoud (1999), entre outros. Tais lições envolvem a importância de se ter critérios claros e objetivos de avaliação, a importância da organização, comunicação e disponibilização de tarefas de forma participativa e, com o envolvimento de todos, a importância do planejamento, da definição de prazos e do gerenciamento do tempo, a necessidade de se dividir o problema 
com o grupo e de não tomar decisões precipitadas, o valor das diferentes opiniões, a ideia de que a motivação é intrínseca e de que ninguém motiva ninguém, entre outras.

Assim, a principal virtude dessa dinâmica, parece ter sido o aprendizado por meio da ação (FREIRE, 2006), pois, de acordo com os próprios participantes, foi na prática que os desafios abalaram a confiança nos demais, os obstáculos ocorreram e, por fim, as dificuldades foram superadas. Isso resultou em um projeto que além de alcançar seus objetivos técnicos, contribuiu para a melhoria da condição de vida de seis crianças especiais, transformando-se em uma experiência que tende a ser mais sólida e duradoura, por envolver também as dimensões afetivas e intelectuais, como afirma Roger (1986).

Portanto, a experiência adquirida não somente com o projeto em si, mas com o contato com a instituição beneficiada, também proporcionou a vivência com situações com as quais os alunos, na sua grande maioria, não estão acostumados a lidar, revelando, de certa forma, o exercício da cidadania e da formação humanista, carente nos cursos de administração.

Todavia, a prática pedagógica inovadora pode representar uma ameaça por constituir-se em uma prática desconhecida e cujos resultados ainda são pouco conhecidos, conforme destaca Mitre et al. (2008). Contudo, a metodologia aqui apresentada demonstrou, não somente pelos resultados alcançados representados pelo comprometimento dos alunos para com o trabalho proposto, mas também pela avaliação da disciplina realizada pelos próprios discentes, que a prática comprometida, crítica e reflexiva acaba por promover a liberdade, a autonomia, o enfrentamento de conflitos e de resistências, proporcionado uma visão do todo, da transdisciplinaridade e da interdependência (PERRENOUD, 2002), as quais devem ser consideradas cada vez mais, tendo em vista a complexidade das situações vividas pelos futuros profissionais (LE BOTERF, 2003), corroborando Santos (2005). 


\section{REFERÊNCIAS}

ALVES, R. Conversas sobre educação. Campinas: Verus, 2003.

BECKER, F. Educação e construção do conhecimento. Porto Alegre: Artmed, 2001.

BERBEL, N. A. N. A problematização e a aprendizagem baseada em problemas. Interface -Comum. Saúde Educação, v.2, n.1, p.139-154, 1998.

CODAS, M. M. Benitez. Gerência de projetos - uma reflexão histórica. Revista de Administração de Empresas - RAE, n. 27, p. 33-37, 1987.

COLL, C. Psicologia e currículo: uma aproximação psicopedagógica a elaboração do currículo escolar. São Paulo: Ática, 2000.

CYRINO, E. G, TORALLES-PEREIRA, M. L. Trabalhando com estratégias de ensinoaprendizado por descoberta na área da saúde: a problematização e a aprendizagem baseada em problemas. Cadernos de Saúde Pública, v. 20, n. 3, p.780-788, 2004.

DEMO, P. Professor do futuro e reconstrução do conhecimento. Petrópolis: Vozes, 2004.

DUARTE, N. As pedagogias do "aprender a aprender" e algumas ilusões da assim chamada sociedade do conhecimento. Revista Brasileira de Educação, n.18, 2001.

DEWEY, J. Democracia e educação. 3.ed. São Paulo: Nacional, 1959.

FREIRE, P. Educação como prática de liberdade. 29.ed. Rio de Janeiro: Paz e Terra, 2006.

LE BOTERF, G. Desenvolvendo a competência dos profissionais. Porto Alegre: Artmed, 2003. MEREDITH, J. R.; MANTEL JR., S. J. Administração de projetos: uma abordagem gerencial. Rio de Janeiro: LTC, 2003.

MITRE, S. M.; SIQUEIRA-BATISTA, R.; MORAIS-PINTO, N. M; GIRARDI-DEMENDONÇA, J. M. ; MEIRELLES, C. A. B.; PINTO-PORTO, C.; MOREIRA, T.; HOFFMANN, L. M. A. Metodologias ativas de ensino aprendizagem na formação profissional em saúde: debates atuais. Ciência \& Saúde Coletiva, v. 13, n.2, p. 2133-2144, 2008.

PERRENOUD, P. Construir competências desde a escola. Porto Alegre: Artes Médicas, 1999. PERRENOUD, P. A prática reflexiva no ofício de professor: profissionalização e razão pedagógicas. Porto Alegre: Artmed, 2002.

PIAGET, J. Sobre a pedagogia (textos inéditos). São Paulo: Casa do Psicólogo, 1998.

PMI - Project Management Institute. Um guia do conhecimento em gerenciamento de projetos (Guia PMBOK). 4. ed. Pennsylvania, 2008.

ROGER C. Liberdade de aprender em nossa década. 2.ed. Porto Alegre: Artes Médicas, 1986.

SANTOS, S. S. A integração do ciclo básico com o profissional no Curso de Graduação em Medicina: uma resistência exemplar. Rio de Janeiro: Papel \& Virtual: Teresópolis: FESO, 2005. 
SCHIMITZ, L. C.; ALPERSTEDT, G. D.; MORAES, M. C. B. Gerenciando projetos: uma experiência de aprender fazendo. Cadernos EBAPE, Edição Especial, p. 1-16, 2008. SCHÖN, D. A. Educando o profissional reflexivo: um novo design para o ensino e a aprendizagem. Porto Alegre: Artmed, 2000b.

SCHÖN, D. A. Educando o profissional reflexivo. Porto Alegre: Artmed, 2000a.

SERVA, M.; DIAS, T.; ALPERSTEDT, G. D. Paradigma da complexidade e teoria das organizações: uma reflexão epistemológica. Revista de Administração de Empresas, v. 50, n.3, p. 276-287, 2010.

VARGAS, R. Manual prático do plano de projeto. Rio de Janeiro: Brasport, 2009.

VASCONCELLOS, C. S. Avaliação da aprendizagem: práticas de mudança. São Paulo: Libertad, 1988. 


\section{DADOS DOS AUTORES}

LEANDRO COSTA SCHMITZ ${ }^{\star}$ leandro@schmitz.eng.br

Mestre em Administração pela UDESC

Instituição de vinculação: Universidade do Estado de Santa Catarina

Florianópolis/SC - Brasil

Áreas de interesse em pesquisa: Ensino de Administração e Gerenciamento de Projetos.

${ }^{\star} A v$. Madre Benvenuta, 2037-ESAG Itacorubi Florianópolis/SC 88035-001

\section{GRAZIELA DIAS ALPERSTEDT gradial@gmail.com}

Doutora em Engenharia de Produção pela UFSC

Instituição de vinculação: Universidade do Estado de Santa Catarina

Florianópolis/SC - Brasil

Áreas de interesse em pesquisa: Estratégia, Estudos Organizacionais, Ensino e Pesquisa em Administração.

HANS MICHAEL VAN BELLEN hans.michael@ufsc.br

Doutor em Engenharia pela UFSC

Instituição de vinculação: Universidade Federal de Santa Catarina

Florianópolis/SC - Brasil

Áreas de interesse em pesquisa: Governança, Sustentabilidade e Indicadores

JANAINA LOPES SCHMITZ janaina.schmitz@sociesc.org.br

Mestre em Contabilidade pela UFSC

Instituição de vinculação: Centro de Educação Superior - UNICA/SOCIESC

Florianópolis/SC - Brasil

Áreas de interesse em pesquisa: Ensino e Pesquisa em Contabilidade 